\title{
A review and case report of pseudologia fantastica
}

\author{
CHERYL D. BIRCH ${ }^{1}$, BRAD R. C. KELLN ${ }^{2}, \&$ \\ EMMANUEL P. B. AQUINO ${ }^{2}$
}

${ }^{1}$ Dalhousie University, Nova Scotia, Canada, and ${ }^{2}$ East Coast Forensic Hospital, Nova Scotia, Canada

\begin{abstract}
A phenomenon of particular interest to forensic mental health workers, the courts, and police is that of pathological lying or pseudologia fantastica (PF). Unfortunately, $\mathrm{PF}$ is an understudied, poorly understood entity. The current diagnostic system captures intentional deception around physical or psychological problems but does not allow for diagnosis around prominent, purposeless deception within other realms (e.g., false accusations). In addition to reviewing the literature around $\mathrm{PF}$, we also report the case of a 22 -year-old female who made frequent, dramatic false accusations against others for no apparent reason, and who possessed an unusual ability to convince others to collaborate in her lying. Her lies eventually resulted in a number of people being criminally charged, including a friend being imprisoned for over a year for staging an elaborate abduction, the burning of an apartment building, and the investigation of a small child for arson. Implications and suggestions for future research are discussed.
\end{abstract}

Keywords: Pathological lying, pseudologia fantastica, deception, false accusations, diagnosis

\section{Introduction}

It is to all who should be acquainted with these striking mental and moral vagaries, particularly in their forensic and psychological significances, that our essay is addressed. In some cases vital for the administration of 
justice, an understanding of the types of personality and of behavior here under discussion is a prime necessity. (Healy \& Healy, 1915, p. 2)

While it has been almost a century since the Healys (1915) authored the first English review of pseudologia fantastica (PF) to enhance awareness about this phenomenon, we propose a similar purpose in writing today. While cases of PF are thought to be quite rare overall, they have now been documented all over the world, and authors reporting on it have continued to echo a concern that there is a need for further case studies and reviews to be published on the topic, further scrutiny of $\mathrm{PF}$ as a psychiatric symptom, and greater awareness of its medical, legal, and social consequences (cf. Akimoto, 1997; Ford, King, \& Hollender, 1988; Newmark, Adityanjee, \& Kay, 1999; Snyder, 1986; Weston, 1996). In this paper, we review definitions of PF by describing core features that reliably characterize those reported to have it in the literature, we review the scant relevant epidemiological data available to date, and we discuss the diagnostic status of individuals who present with symptoms of PF. Then, we present a case report of a young woman whose persistent and fantastic lies were of a false accusation variety. We discuss the relevant diagnostic issues, and the unusual collaboration in lying that occurred in this case. We conclude with recommendations for future research, and a summary of forensic implications and clinical interventions for $\mathrm{PF}$.

\section{Core characteristics of PF}

The term 'pseudologia phantastica' was originally coined by a German psychiatrist in the late 19th century. An early synonym for PF was 'mythomania,' and it is often used interchangeably with the term 'pathological lying' (Akimoto, 1997; Deutsch, 1922/1982; Healy \& Healy, 1915; Newmark et al., 1999). Regarding the use of this latter term, however, some argue that there is more than one type of pathological lying, and that PF is only the most severe subtype of such lying (King \& Ford, 1987; Sharrock \& Cresswell, 1989; Snyder, 1986; Wiersma, 1933). Such issues related to the theoretical conceptualization of PF are likely to remain controversial, as they are difficult to investigate empirically. Nevertheless, the clinical picture of PF is often strikingly uniform, and thus many authors agree about its central features, which include a marked tendency to lie (e.g., Hardie \& Reed, 1988; King \& Ford, 1988).

It is widely accepted that essential components of a lie include a consciousness of falsity, and an intent to deceive (cf. Ford et al., 1988). Most lying is a normal phenomenon and plays a role in everyday life. It occurs normally during the development of mental autonomy as children learn to recognize that their parents cannot access or control their thought life (cf. Ford et al., 1988; Weston, 1996). Selling (1942) notes that 
'everybody lies and you can't stop them, and of course that is the truth' (p. 336). Normal lies are often defensive in an attempt to avoid the consequences of truth-telling (Selling). They are often tactful or altruistic 'white lies' that can spare another's feelings, reflect a pro-social attitude, and make civilized human contact possible (Ford et al., 1988; Deutsch, 1922/1982; Selling, 1942).

However, pathological lying, as in PF, is quantitatively and qualitatively distinct from 'normal' lying. Quantitatively, it must be excessive and chronic. Healy and Healy (1915) describe, for example, that individuals with PF tend to 'indulge in a veritable orgy of lying' (p. 25). Indeed, lying in $\mathrm{PF}$ is so excessive that it often appears impulsive, and to be associated with at least some dyscontrol (Hardie \& Reed, 1998; Healy \& Healy, 1915; King \& Ford, 1988). In terms of chronicity, some have suggested that the lying should be persistent from adolescence or early adulthood (cf. Akimoto, 1997). In their review of 72 cases of PF, King and Ford (1988) found that the average age of onset was 16 and that the average age at time of report was 22. Overall, one can conclude that PF manifests itself most frequently as a trait rather than an episode (cf. Healy \& Healy).

As many people lie frequently, PF cannot be identified on the basis of excessive lying alone, but the qualitative nature of the pseudologue's lies is also quite distinct (cf. King \& Ford, 1988; Weston, 1996; Wiersma, 1933). While the theme of lies can be stereotyped or varied in nature (Deutsch, 1922/1982), they are almost always dazzling or fantastical, and often develop into a complicated system of deception. The imaginative fluency of the lies tends to capture public attention, at least in the short term. The lies must keep a certain reference to reality, and though they are often unlikely, they are not beyond the realm of possibility (e.g., 'I communicate with aliens') (cf. Sharrock \& Cresswell, 1989; Snyder, 1986). Under close scrutiny the lies can often be easily discredited, and for this reason the lying in $\mathrm{PF}$ is frequently noted to be destructive to the liar (cf. Akimoto, 1997; Hardie \& Reed, 1998; Healy \& Healy, 1915).

Along the same lines, there is good consensus in the literature that a most important distinguishing and differential, qualitative feature of lies in PF (vs. normal or non-pathological lies) is the lack of an obvious motive for lying (cf. King \& Ford, 1988; Weston, 1996). Healy and Healy (1915) offer that 'the cardinal point of recognition of this class of conduct may at once be stated to be its apparent baselessness' (p. 2). Deutsch (1922/1982) describes that 'whereas a lie is usually goal-directed and for a reason, pseudology, like poetry, can be a gratification in itself (p. 371). This apparent purposelessness is thought to be due to the fact that internal psychological (and often unconscious) motives for lying predominate, rather than pre-conceived external motives (e.g., legal or financial gain and/ or avoidance of punishment or responsibility) (Akimoto, 1997; Hardie \& Reed, 1998; King \& Ford, 1988; Newmark et al., 1999; Sharrock \& 
Cresswell, 1989; Weston, 1996; Weston \& Dalby, 1991; Wiersma, 1933). If there are external motives evident in cases of PF, these must be secondary to internal reasons for lying. For example, Hardie and Reed report a case of $\mathrm{PF}$ with impostership, and note that the elaborate deception that occurred in this case was far beyond what was necessary to swindle successfully.

Many authors have speculated about the nature of internal, intra-psychic motives that stimulate pseudology. Healy and Healy (1915) note: 'All pathological liars have a purpose, i.e., to decorate their own person, to tell something interesting, and an ego motive is always present. They all lie about something they wish to possess or be' (p. 16). They often depict themselves as a hero or victim in their concocted imaginary adventures (King \& Ford, 1988). The social attention attracted by their lies may provide them with a transient escape from a reality that is perceived as painful or uninteresting (cf. Enoch \& Ball, 2001; Deutsch 1922/1982). Deutsch further refers to a lie in PF as 'the fantasy lie' and as a 'daydream communicated as reality' (p. 373). Ford et al. (1988) summarize many possible internal motives for PF including autonomy, the need for regulation of self-esteem, repression or denial of reality, power or aggression (at being able to dupe another), and wish fulfillment.

Thus, through the classification of the main underlying motive for lying as either internal or external, people with $\mathrm{PF}$ can be distinguished from those who con and manipulate others merely for external gain or profit. While it seems clear that the distinction between internal and external motives for deception is not always easily made, there is a consensus in the literature that it can generally be made with good reliability. Additionally, making this same distinction is necessary, and hence believed achievable, for the differential classification of deception about illness as either a factitious disorder or malingering (American Psychiatric Association, 2000). Nevertheless, the task of testing motives is always deserving of careful analysis, and previous literature, on both PF and factitious disorder, has not always provided clear guidance on how this is best accomplished.

Several examples can be offered of when it is difficult to distinguish internal from external motives for deception. While it may be fairly easy to establish that there is an external, rather than internal, motive for lying in many cases, like when there is a potential for monetary gain, or avoidance of obligation or punishment (e.g., conscription to the military, or incarceration for a crime), it may be more difficult to discern an external incentive for lying when the threatened punishment is more mild. As the following two examples illustrate, however, it is possible to distinguish externally motivated lies told to avoid social rejection or disapproval from internally motivated lies told to win social admiration or approval. The externally motivated lie is when one says of a neighbour's cherished but dilapidated old vehicle, 'Yes, I think your car is fabulous.' In an internally motivated lie the pseudologue boasts, 'I have ten vintage-style sports cars, 
all in top condition, at my large, private estate in Monaco.' The former lie may be reflexive but strategically (consciously) defensive to avoid the neighbour's disapproval, whereas in the case of the latter the pseudologue may not be readily conscious of, or willing to admit, the precise motive (e.g., enhance social esteem, wish-fulfillment) that stimulated the impulsive claim. The key difference between these lies is that the external motive for the first is more obvious, as it is told to have an impact on a situation in the external environment. In contrast, the internal motive for the second is not readily obvious, as it can only be understood with a consideration of the intra-psychic, rather than external, environment (cf. Ford et al., 1988).

It may also be particularly difficult to distinguish internally from externally motivated lies in the case of false accusation. For example, false accusation for revenge may seem to be driven by an internal state, but it can be most easily understood as a strategic, profit-motivated reaction to a situation in the external environment (cf. Healy \& Healy, 1915). The telling of the lie is not gratification in itself, but instead gratification is derived from the vengeful effect the lie will have in an external situation. Even in the case of false self-accusation, if the purpose is to conceal the guilt of another this may also promise external gain (e.g., prevent a loved one from facing punishment). In contrast, purposeless self-impeachment is especially convincing of abnormality (Healy \& Healy; Sharrock \& Cresswell, 1989).

In continuing to describe the core characteristics of PF it is necessary to differentiate lies in PF from delusions. In fact, pseudologues may be so invested in their lies that they cannot adequately discriminate fantasy from reality (cf. Akimoto, 1997; King \& Ford, 1988; Powell, Gudjonsson, \& Mullen, 1983; Snyder, 1986; Weston, 1996). Wiersma (1933) notes that the liar may tell his story with such zeal that he may convince himself of its truth. He argues that there must, in fact, be evidence of a defective distinction between fiction and reality to justify a diagnosis of PF. But the pseudologue must hold at least some capacity to recognize his or her deception when confronted with it, while the individual with delusional disorder, in contrast, cannot (King \& Ford, 1988; Weston, 1996; Wiersma, 1933).

In addition to distinguishing lying in PF from delusions, many authors argue that the lies must not be better accounted for by another major abnormality, such as confabulation or low intelligence (cf. Healy \& Healy, 1915; King \& Ford, 1988). Confabulations are similar to delusions, and distinct from pseudologia, because the confabulator cannot often admit consciousness of falsity (cf. Ford et al., 1988; King \& Ford, 1988). Instead, with confabulations there is an 'unconscious filling in of memory gaps with imagined experience' (Weston, 1996, p. 111). In addition, confabulation is almost always associated with some organically-derived memory impairment (Ford et al., 1988; King \& Ford, 1988). While some authors have noted that PF may also be associated with neurological deficits (cf. Ford et al., 1988; Modell, Mountz, \& Ford, 1992), Healy and Healy (1915, p. 1) 
asserted that patients with PF cannot be declared 'insane, feebleminded, or epileptic.' They claimed 'the main classification of an individual should be decided by the main abnormal condition' (p. 1).

In summary, there is consensus in the literature about the central features that characterize $\mathrm{PF}$ and distinguish it from other classes of aberrant behaviour. These features include excessive, impulsive lying that usually has an onset in adolescence and is of chronic duration. Lies in PF often have a fantastical quality, are easily verifiable, and are destructive to the liar. In addition, the lying is primarily stimulated by internal, psychological motives (e.g., self-esteem regulation or fantasy fulfillment), rather than by external, situationally-determined motives (e.g., financial gain or punishment avoidance). Finally, there is often an impaired distinction between fiction and reality, but this impairment is not of delusional severity, or due to organic memory impairment.

\section{Epidemiological data for PF}

There is very scant information available to date about the prevalence, demographic correlates, and consequences of PF. The vast majority of researchers and clinicians who have reported $\mathrm{PF}$ since it was first documented, almost a century ago, tend to agree that there is a low prevalence of individuals in the general population who present with all or most of the core characteristics of PF, as described above (cf. Weston, 1996). Wiersma (1933), for example, notes that 'patients presenting the well developed syndrome of mythomania are not at all frequent' (p. 48). The only research to date on actual prevalence rates, however, was conducted by Healy and Healy (1915), and this data collection was limited to a large sample of juvenile offenders. In this sample of 1,000 repeat juvenile offenders, 104 males and 80 females $(15 \%$ and $26 \%$ of the total male and female population, respectively) were notorious for their frequent lies. Among these liars, however, Healy and Healy concluded that only about eight or ten of them (approximately $1 \%$ of the total sample) displayed a pattern of lying consistent with the clinical picture of PF or pathological lying. Further research on prevalence is sorely needed. It is noteworthy, however, that a $1 \%$ estimated prevalence rate of PF (though it may be somewhat lower in a non-forensic population) is consistent with the estimated prevalence rate for deception about illness (i.e., factitious disorder).

In addition to the Healy and Healy (1915) sample, demographic information about PF can also be gleaned from King and Ford's (1988) synthesis of information from 72 case reports of PF in the literature. King and Ford found an equal gender distribution, with half of their cases being female and half male, though Healy and Healy believed a greater proportion of females vs. males presented with PF. As mentioned, King and Ford found a typical onset during adolescence, and an age at first report typically 
occurring during young adulthood. When intelligence was reported in the King and Ford cases it was typically found to be average or above average, and several cases showed significantly superior verbal vs. performance abilities. Half of the pseudologues in this study were reported to engage in crimes such as theft, swindling, forgery, and plagiarism, and $20 \%$ had a history of psychiatric hospitalization. There was thought to be a chaotic home environment in about $30 \%$ of these reported cases, with either a parent or family member also presenting with a mental disturbance.

\section{Diagnostic issues}

The diagnosis of PF, mythomania, or pathological lying has not appeared in any of the editions of the Diagnostic and Statistical Manual of Mental Disorders (DSM; APA). Some theorists propose that PF can occur as a feature of several personality disorders (e.g., antisocial, borderline, narcissistic, and histrionic personality disorders; Ford et al., 1988; Snyder, 1986). Indeed, the DSM-IV-TR (APA, 2000) notes that deception can occur as a symptom of some of these disorders. People who display classic characteristics of PF may not, however, prominently display any or all of the other symptoms required for a diagnosis of these disorders. Many have argued that none of these personality disorders adequately account for the prominence or purposelessness of the prevaricating that occurs in PF (cf. Akimoto, 1997; Hardie \& Reed, 1998; Healy \& Healy, 1915; King \& Ford, 1988; Wiersma, 1933).

PF may first be most obviously distinguished from antisocial personality disorder (ASPD) because the deceit in ASPD, unlike in PF, commonly occurs for external personal profit or pleasure, such as to gain money, sex, or power (APA, 2000). Also, as noted above, only about half the individuals with PF are thought to commit crimes, and if they do commit crimes these are not reported to involve physical aggressiveness or a reckless disregard for safety (King \& Ford, 1988). Additionally, individuals with PF may not have a history of conduct disorder, and there is preliminary evidence that they do, in fact, display guilt about their deception (Powell et al., 1983). Unlike psychopaths, there is evidence that individuals with PF show physiological arousal or stress (normal 'guilty' responses) when lying during a lie-detection test (Powell et al.). Interestingly, this guilt about lying may in fact motivate individuals with PF to believe in their lies for guilt-reduction (if their lies were true they would not have to feel guilty), and this, in turn, could explain their impairment in distinguishing fact from fantasy (cf. Powell et al.).

The personality presentation of individuals with PF may also be quite distinct from that of individuals with borderline personality disorder (BPD). First, deceptive behaviour is not specifically listed as a symptom of BPD in the DSM-IV-TR, and this raises doubt as to whether such a diagnosis could ever fully account for the prolific prevarication in PF. 
Individuals with BPD, however, often make frantic efforts to cope with their emptiness and avoid abandonment, and this may include making empty threats that they will engage in parasuicidal behaviours, or false accusations of mistreatment or rejection. While lies in PF may be stimulated by a perceived need to enhance social status or self-esteem, they may not be typically induced by intense abandonment concerns. Also, PF may not be associated with the affective dysregulation, parasuicidal behaviour, or unstable sense of self that is typical with BPD. In fact, contrary to this latter symptom, individuals with PF often possess a good deal of 'personal vigor' and 'self-assurance' that can help them command success with their lying (cf. Weston, 1996, p. 107).

There may also be both shared and distinct personality tendencies among individuals with $\mathrm{PF}$ vs. histrionic and narcissistic personality disorders. Manipulative attention-seeking may be common among individuals with any of these temperamental tendencies. As in BPD, however, deceptive behaviour is not listed as a central feature of either histrionic or narcissistic personality disorder. And individuals with PF may primarily present as non-sexually and verbally dramatic, instead of appearing physically and sexually flamboyant, as is common among individuals with histrionic disorder. Contrary to individuals with narcissism who are exploitative and unempathetic, and who believe they have already achieved perfection, many individuals with PF do not show these antisocial tendencies, and they commonly lie about their lives or circumstances precisely because they perceive them to be imperfect or uninteresting (Deutsch 1922/1982; Enoch \& Ball, 2001; King \& Ford, 1988; Wiersma, 1933).

Thus, these personality disorders may not fully account for the prominence, or unique style, of lying that occurs in PF (cf. Akimoto, 1997; Hardie \& Reed, 1998; Healy \& Healy, 1915; King \& Ford, 1988; Wiersma, 1933). The possibility of a comorbidity of PF with these disorders, however, should always be carefully considered (Hardie \& Reed, 1998; Newmark et al., 1999; Weston, 1996). It has been suggested that PF could be identified within our current diagnostic system as a personality disorder, not otherwise specified (NOS; cf. Akimoto, 1997). Assigning an NOS diagnosis may, however, be problematic, particularly in cases of PF, as other professionals who work with recipients of this diagnosis may not be alerted to any of the specific behaviours associated with their diagnosis. Thus, such a diagnosis may not provide enough information to make its assignment worthwhile.

The only diagnosis available in our current diagnostic system that does account for prominent, purposeless (internally motivated) deception is the Axis I factitious disorder diagnosis. Thus, pathological liars may only qualify for a diagnosis (i.e., of factitious disorder) if the theme of their lies centers around the simulation of a physical or psychological disorder. Hardie and Reed (1998) describe it as an artificial limitation of our 
diagnostic system that deception about illness is considered diagnostically significant, while deception about other topics, such as one's identity (i.e., impostership) is not-particularly because these two types of deception can co-occur with equal severity. Indeed, individuals who simulate illness are commonly also noted to display what is referred to as PF; when referred to in this manner PF is meant to denote a pattern of lying about topics other than illness (APA, 2000; Enoch \& Ball, 2001; Ford, 1982).

We are in agreement with those who suggest it is artificial to recognize the diagnostic significance of illness-simulation deception with one term (i.e., factitious disorder), and to reserve another term (i.e., PF) for deception about non-illness-related themes, which are not considered diagnostically significant. The predominant feature of both of these syndromes is purposeless, conscious deception. Hardie and Reed, as well as King and Ford (1988), suggest that a single term such as 'deception syndrome' or PF should be used to characterize this primary deceptive tendency, and that stereotyped deception about illness or identity (i.e., imposture) should be considered as secondary behavioural manifestations, or subtypes, of this primary syndrome. We propose that the term PF or deception syndrome should also account for a manifested subtype of conscious, purposeless deception involving themes of false accusation. Several authors have noted that lies of false accusation are, in fact, common among individuals with PF (cf. Enoch \& Ball, 2001; Healy \& Healy, 1915).

Below is the case report of Lorraine, a young white female who displayed all the core features of PF noted above, and who engaged in pathological false accusation. While we believe this to be a rather typical case of PF, Lorraine also demonstrated an unusual ability to recruit others to propagate her lies in a manner that also appeared to be pathologically significant.

\section{Case report}

Lorraine $^{1}$ was 22 years old when she was remanded to a secure forensic psychiatric facility for an assessment of fitness to stand trial and criminal responsibility for three arson-related offenses, two counts of public mischief (false reports), three counts of making false statements, two counts of fabricating evidence, and one count of perjury. Information was obtained for this case report from interview notes and reports written during Lorraine's forensic hospitalization, from reports written during one of Lorraine's previous psychiatric hospitalizations, from copies of police files obtained from the crown attorney's office, and from reports written when Abby (one of the victims of Lorraine's lies) was hospitalized on two occasions for psychiatric assessment.

These records provide information about Lorraine's early social, developmental, and academic history. Lorraine is an only child who was born out of wedlock. Her biological father has been absent since birth. Her 
birth was apparently normal, she achieved all her developmental milestones at the appropriate age, and she was physically healthy throughout her childhood. Lorraine was raised by her grandparents until she was 13 years old, and until her mother gained some control over her mental health problems (eating disorders, benzodiazepine dependence, depression, and Axis II traits). In terms of additional family psychiatric history, Lorraine has a maternal aunt with schizophrenia. Lorraine was a good student academically, but her teachers wrote several reports of ongoing, attention-seeking, problem behaviours occurring during her teenage years (e.g., 'losing her books only to have another student find them wrapped in plastic in the woods, false accusations of others' conduct and/or attitudes toward her, expectation that she should receive special treatment by teachers, and entering into relationships with students where she could maintain the dominant role of influence').

Lorraine's first psychiatric treatment was when she was 16 years old and admitted to hospital following a suicide attempt. She was diagnosed with, and treated for, bipolar mood disorder. During that admission she reported persistent depressive symptoms, as well as recent manic-type behaviours she claimed were uncharacteristic (e.g., entering a mall and singing spontaneously in front of a crowd, and attending a stranger's funeral to make conversation with the family of the deceased). At this time she also spoke of significant family conflict with her mother and stepfather, including a concern that her stepfather was going to kill her.

During her forensic psychiatric assessment, Lorraine was asked about her early behaviour and former hospitalization. She said she would often do things that were foolish and that she would later regret. Contrary to what she claimed during her previous hospitalization, she said it was not out of character for her to take a friend and attend a stranger's funeral. She said she found it amusing and 'would make up stories on the spot.' She also admitted to inventing the previous concern that her stepfather was trying to kill her. She said she loved drama, was in several school plays, and enjoyed 'carrying on.' She thought her life was boring so she would have fun exaggerating. She said she is good at 'conning people.' 'I just keep lying to cover what I was saying initially.' During her forensic assessment there was no evidence to support a diagnosis of bipolar mood disorder.

Lorraine's major involvement with the legal system occurred when she was between the ages of 20 and 22. Occupationally, around this time in her life, she reported working at a variety of odd jobs (e.g., working as a clerk for three weeks at a department store), but said she was unable to stay in one job long due to boredom. She eventually became a recipient of social assistance. She began living with a man 20 years her senior, and had a child with him.

Lorraine's first major accusation occurred when she reported to the police receiving numerous menacing death threats over the telephone and in a letter from Vera, one of her female co-workers. Allegedly, Vera wanted Lorraine 
dead because she felt Lorraine was 'interfering' in her relationship with her boyfriend. The content of the letter Lorraine submitted to police was graphic and dramatic: 'You will die choking on your own blood. You are a walking image of death.' As a result of Lorraine's allegations during this first incident, Vera was arrested and released with a notice to appear in court, and conditions to avoid all contact with Lorraine. Lorraine, however, eventually terminated her complaint when police became suspicious of the postmark on the letter, and requested that Lorraine submit to a polygraph test.

About a year after this first major accusation, Lorraine made reports to police that Abby, her best friend since early grade school, had begun stalking her and, as in the case of Vera, had made numerous death threats over the telephone and in letters sent to Lorraine. Allegedly, Abby had suddenly developed a lesbian attraction to Lorraine and had become enraged when Lorraine did not reciprocate the romantic feelings. The threats were again very dramatic (e.g., 'If I can't have you no one will'), and the letters Lorraine submitted to police contained threatening items that Abby had allegedly enclosed (e.g., a stolen and cut-up pair of Lorraine's underpants, as well as photographs taken of Lorraine that were punctured around her neck). When confronted about the threats, Abby apparently became so distraught that she agreed to seek help at the hospital. Abby had had no previous contact with the mental health system, was completing a science degree at university, and had plans to become a schoolteacher. Throughout two weeks of hospitalization on a psychiatric ward Abby never denied making threats or being obsessed with Lorraine. Hospital staff felt Abby still posed a threat to Lorraine, though they felt there was no clear diagnosis for her behaviour. Upon her discharge from hospital Abby was charged with uttering threats and criminal harassment, and ordered to avoid all contact with Lorraine.

Two weeks later Abby allegedly abducted Lorraine at knifepoint from her residence. This abduction was a very dramatic ordeal that was widely publicized in the media at the time, and elicited an immediate response from the police Major Crime Office and specialized crisis negotiators, as this incident was classified as a life-threatening situation. Abby had apparently punched Lorraine, cut her shirt, and was forcing her to drive her own car at knifepoint across the province. Abby made several phone calls to Lorraine's relatives during this time saying she was 'obsessed with Lorraine and the only way to get freed from the obsession was to kill her.' During her last phone call she screamed that she had killed Lorraine. The location of the vehicle was determined by using the cell phone signal and eventually the vehicle was stopped. Lorraine had not been killed and she fled from the car to police when the vehicle was stopped. Abby dropped a butcher's knife at gunpoint and was taken into custody. Abby received an assessment at a secure forensic psychiatric facility, and it was found that she should be tried as criminally responsible for charges of uttering threats, 
kidnapping, and assault. As it was felt she still posed a threat to the 'victim' she was incarcerated to await her trial. Over the course of these events Abby did not once deny her rage at the rejection or her intention to kill Lorraine.

Shortly after the abduction Lorraine allegedly had a severe anxiety attack and was rushed to hospital by ambulance where she was diagnosed with, and treated for, PTSD. After seven months, however, Lorraine had regained sufficient emotional fortitude to testify under oath, at a preliminary hearing, that Abby had threatened her and kidnapped her against her will. She also claimed that Abby had continued to make threatening phone calls to her from prison. Following this hearing, Abby remained in prison for nine more months while awaiting her trial.

Next in the saga of Lorraine's life, and about a year after her alleged abduction (while Abby was still in prison), Lorraine reported to police receiving yet another set of death threats over the telephone, as well as through dramatic letters and photographs sent to her. The alleged perpetrator in this case was her fiancé's ex-wife, Kara, who apparently wanted Lorraine dead for stealing her husband. Lorraine's fiancé, in this case, also told police that he had received telephone threats that Kara would kill Lorraine. Lorraine further alleged that Kara was tied to her prior kidnapping, and had originally plotted with Abby to have her killed. Kara was arrested and charged with uttering threats.

Soon after this, Lorraine was involved in another dramatic scenario, and made another accusation before any solid suspicion about her reliability was raised. She accused her fiancé's three-year-old son of starting two separate fires. The first fire destroyed a bedroom in Lorraine's mother's uninsured apartment, and sent family members (including Lorraine's two-month-old infant) to hospital with smoke inhalation. The three-year-old readily confessed to lighting the fire, though he was not even in the apartment when the fire began. The next night a fire broke out in Lorraine's own apartment. This fire sent the three-year-old to hospital with second-degree burns and it devastated the apartment building, rendering all the tenants homeless. Again the three-year-old confessed to lighting the fire. When it was found improbable, however, that the small boy could have set the fires, Lorraine was called in for questioning by police.

By this time, Lorraine's pattern of dramatic allegations had caught the attention of legal authorities and when pressed during questioning, she quite readily confessed that all of her allegations made within the past two years had in fact been fabricated. Her confession, however, did not seem to deter her further habitual fabricating, even when it was more blatantly transparent; she told her family and friends when she was arrested that she had to 'go along with the charges' because the police were conspiring with Kara and Abby to kill her.

During her forensic assessment for criminal responsibility, Lorraine was asked about each deception related to her charges. In the case of Vera, she 
admitted that she had not received any telephone threats, and that she had mailed the letter with the death threats to herself. She said of this accusation, 'I don't know why I did it. It was stupid. It was just one thing that happened at work. I just got carried away.' When asked what she had against Vera, Lorraine replied, 'Nothing. I don't have anything against Vera. Vera is a nice girl.'

Lorraine's incentives for her accusations against Abby were similarly obscure, as Lorraine noted that Abby had been her best friend since they were in Grade 3 together. Lorraine said she had initially told Abby that her life was in danger because she knew someone who had witnessed a local murder. Apparently, she invented a story about how this threat of danger would be alleviated somehow if Abby were to abduct her. Thus, Lorraine admitted that Abby had staged the whole crime on her orders, and that she herself had fabricated all the threats. This confession did not come, however, until after Lorraine had testified against her friend in court (months after the abduction), after Abby had already spent 16 months in prison, and after Lorraine was caught and pressured to confess to her other criminal behaviours. Lorraine claimed she felt very guilty about not stepping forward to exonerate her friend, especially since Abby could have been sentenced to a federal penitentiary for 12 years for kidnapping. She said, however, she had 'no idea' why Abby did not tell the truth herself. After Lorraine had made her confession, Abby also finally admitted to police that the whole abduction had been staged at Lorraine's insistence, and she was immediately released from prison. Upon her release, Abby said she thought she was 'helping' Lorraine, and that she did not harbor any ill will towards her. Abby was unfortunately not available for further interview.

Lorraine admitted that all her accusations against her fiancé's ex-wife (Kara) and three-year-old son were also false. In the case of Kara, Lorraine said that she, herself, had again procured the letters and photographs, and that she had instructed her fiancé to corroborate her lies to police. Lorraine said she felt guilty that her fiancé's three-year-old was being blamed for setting the fires. She stated she lit the fires because she felt that she and her fiancé should 'have a fresh start... away from Kara and Abby.' She further said that, 'For whatever reason, I kept thinking how wonderful it would be as a family if Kara and Abby would just leave us alone.' She also said that by blaming her boyfriend's son for the fires she had hoped that people would recognize that he 'needed help' and should not be allowed to stay with his mother, Kara, because she was (allegedly) abusing him.

\section{Case discussion}

Lorraine exhibited virtually all of the behaviours that have been previously associated with PF. Her lying was excessive and chronic. She was 22 at the 
time of her forensic psychiatric assessment, and documentation of her problematic lying traced back at least to when she was 16. As noted previously, age 16 at onset, and 22 at first report were the mean ages reported for cases of PF by King and Ford (1988). While chronic, frequent lying is not in itself sufficient to suggest that Lorraine has PF, Lorraine also exhibited a unique style of lying that is consistent with what has been reliably reported as typical of PF.

Many of Lorraine's lies were stereotyped in content as fantastical lies of false accusation (even tracing back to when she was 16), and false accusation is common in PF (cf. Enoch \& Ball, 2001; Healy \& Healy, 1915; Snyder, 1986). Pseudologues are notorious for casting themselves as either hero or victim in the imaginary adventures they report as reality (cf. King \& Ford, 1988), and Lorraine specifically preferred to depict herself as the victim of 'cruel and unusual' death threats and dramatic criminal scenarios. As mentioned, the fantastic quality of lies in PF has been well reported, and it is interesting to note that, like Lorraine, a history of having a love for the dramatic is not uncommon among cases of PF (cf. King \& Ford). Healy and Healy (p. 20) state that 'a considerable number of our group were characterized as great talkers, and several as romantic, dramatic, fantastic, etc., even by ordinary observers.'

As mentioned, it can be difficult to distinguish internal from more normative, external motives for lying, but we believe it can be clearly established that, consistent with PF, internal motives predominantly prompted lying for Lorraine. First, it is clear that her lying was never initiated for any of the most common external motives. Her lies were not altruistic, white lies, and she did not lie to obtain money, sex, or a higher title (power) in her external environment. (She may have lied to enhance her social esteem or to feel power at being able to dupe another, but these incentives for lying would have been driven primarily by internal, psychological needs, and they are not easily understandable as a reaction to a situation in the external environment.) While she may have maintained her lying, in part, to avoid the social or legal consequences of admitting to her prior deceptions, her lies were never initiated to avoid punishment.

As noted, it can be particularly difficult to distinguish internal from external motives for lying in cases of false accusation. In the case of Lorraine, three people were charged with criminal offenses as a result of her accusations, but there is no clear evidence of any revenge incentive that might account for more normative (externally motivated) false accusation. Lorraine described two of the people she made allegations against as her friends. Abby (who was imprisoned for over a year because of Lorraine's lying) had in fact been best friends with Lorraine since they were eight years old. In the case of Vera, Lorraine said, 'Vera is a nice girl,' that her accusations were 'stupid,' that she 'got carried away,' and that didn't know why she did it. It is possible that Lorraine's accusations against Kara were 
somewhat motivated by a revenge-type incentive, perhaps because she felt threatened by her fiancé's ex-wife. Her fiancé, however, knew that Lorraine's accusations against Kara were false (e.g., Lorraine instructed him to corroborate her lies about Kara to police). Thus, it is not likely that her lying caused her any situational benefit typically sought with revenge (e.g., her lying probably did not cause further estrangement between her fiancé and his ex-wife or provide her with any more relationship security). Consistent with a test for internal motives in PF, her 'falsification (in this situation) seemed entirely disproportionate to any discernible end in view' (Healy \& Healy, 1915, p. 1). Also, in the case of her accusations of arson against her fiancé's son, it is not clear how she meant for her behaviours to provide her with any sense of a 'fresh start' with her family, or how anyone would immediately conclude that the three-year-old 'needed help' or was being abused by his mother even if they did believe that he had lit the fires. Her accusation here resembles Munchausen by proxy because it seems she was trying to fabricate psychological symptoms in her fiancé's son to gratify her own need to make false accusations, or to role-play some fantasy.

The fact that Lorraine's lies often proved easily verifiable and eventually to thwart her own interests also attests to the fact that the goals she hoped to achieve by lying were internal, rather than preconceived and external, in nature. With respect to the arsons, for example, the fire inspectors quickly concluded that the three-year-old was not capable of using a childproof lighter to light the fires (especially since he was not even present when the first fire was lit). As is sometimes common among pseudologues (cf. Powell et al., 1983), Lorraine failed to take even minimal precautions against her lies being detected in this situation, indicating that it was difficult for her to resist the immediate, internal gratification afforded by her lying.

During her forensic assessment Lorraine admitted she did not really know why she lied, but the insights she could offer also suggest she had primarily internal vs. external motives for lying. She said:

When I get this excitement, it's fun for a little while but then it gets overwhelming .... I was laughing at what I was gaining from the situation but not from other people's suffering. I knew how to start it and I don't know how to stop. And that's when I get into trouble. I get the result that I want for myself but I didn't want the other person to get in trouble. I couldn't go and tell later on that I lied.

She also shared her belief that 'families only become close when something tragic happens.' She said that after a tragedy, her family focuses on the tragedy and that 'takes the pressure off me.' She no longer feels guilty about her personal shortcomings, or not having work. Overall, it seemed clear from interviews that Lorraine's lying was strongly driven by internal needs such as the need for excitement, attention, and enhanced self-esteem, as 
well as for emotional closeness and sympathy from family members and friends.

In further delineating the features of Lorraine's pseudology that are typical of $\mathrm{PF}$, there are several indications that she had impaired reality testing. When asked, for example, about the incident when she was rushed to the hospital by ambulance shortly after her alleged abduction, she said the doctors thought she had 'taken a flashback' (to the abduction), and she recounted this incident as if the doctors had discovered the truth in the matter about her having PTSD. Similarly, she claimed she lied at the preliminary hearing about Abby making continual threats against her from prison, because she was 'tired of not being taken seriously.' She seemed to believe that by telling this lie, 'justice' would prevail more quickly, that Abby would be sentenced to a punishment befitting her original 'crime,' and thus, that she would be better protected from the 'threat' posed by Abby. With respect to the arson, she said she lit the fires to have a 'fresh start' with her fiancé and family, and so that Kara and Abby would 'just leave us alone.' She clearly seemed to have convinced herself that Kara and Abby posed a real, and continual, threat to her life, even though the threat they posed had only been fabricated in the first place, Kara and Abby had never even met each other, and Abby had been in prison for about a year when Lorraine was role-playing this fantasy that stimulated her fire-setting.

\section{Diagnostic issues relevant to the case}

We believe that Lorraine's prominent, purposeless lying presents in a manner that is highly consistent with the clinical picture of PF that has been reliably documented in previous literature. Overall, her frequent false allegations were fantastical, internally motivated, and impulsive, and she seemed to have at least some difficulty distinguishing fact from fantasy. Lorraine's lying caused severe disruption and distress in her own life and in the lives of many other people, and thus it is unfortunate that her PF is not definable within our current diagnostic system. As noted earlier, conscious, purposeless deception about themes other than illness (e.g., false accusation, identity, or imposture) is not considered diagnostically significant.

On various occasions Lorraine displayed behaviours that may have warranted a diagnosis of factitious disorder, or factitious disorder not otherwise specified. During Lorraine's forensic assessment when she was 22 years old there was no evidence she suffered from bipolar mood disorder, and when she discussed her previous psychiatric hospitalization during this assessment she admitted she had been less than truthful in describing the nature of the symptoms that lead to her earlier diagnosis with bipolar disorder. As noted briefly above, she seemed to display behaviour consistent with factitious disorder by proxy when she set the two fires and blamed her fiancé's three-year-old. Additionally, when Lorraine was rushed 
to hospital by ambulance with panic symptoms a few weeks after her alleged abduction, there is evidence she may have been feeling genuine anxiety about the consequences of her lying for both her family and friends. Whatever she felt, however, we can be certain that it was not PTSD, the diagnosis for which she received ongoing treatment and, in fact, did not dispute.

As may be typical for individuals with PF, Lorraine's lying does not seem to be better accounted for by any of the most relevant personality disorders (e.g., antisocial, borderline, histrionic, or narcissistic personality disorders). During her forensic assessment it was found that none of these disorders accounted for the prominence or purposelessness of Lorraine's prevaricating and, in addition, she did not clearly display a sufficient number of the non-deception-related symptoms required for other diagnoses. She clearly had antisocial traits. Her deceptions created painful consequences for many people (e.g., wrongful criminal charges, Abby's wrongful hospitalizations and incarceration for 16 months, smoke inhalation, burns, and property damage among family members and fellow tenants in her apartment building), and any remorse she felt was not sufficient to prompt her to confess to her past prevaricating, or to prevent her from making further false allegations. Yet she did appear to experience some guilt about lying, and, as with other pseudologues, her difficulty distinguishing fact from fantasy could reflect her efforts to believe in her lies for guilt reduction. Inconsistent with ASPD, Lorraine had internal, rather than external, motives for deception, she was not physically aggressive, and she did not have a history of conduct disorder. Inconsistent with BPD, Lorraine did not display parasuicidal behaviours or marked affective dysregulation, and her dramatic and elaborate deceptions did not seem to be driven by intense abandonment concerns. Like most other pseudologues again, and inconsistent with BPD, she clearly possessed a self-assuredness that was necessary for her to be persuasive in her lying (e.g., to delude police repeatedly and attend a stranger's funeral to make conversation with the family). Inconsistent with histrionic personality disorder she was not flirtatious or flamboyant in her physical appearance, and inconsistent with narcissistic personality disorder she lied precisely because she believed her life was boring and she was interpersonally inadequate and inferior.

\section{A case with pathological collaboration in lying?}

The fact that Lorraine was repeatedly able to convince others to lie for her is also noteworthy, and deserving of clinical scrutiny; it had tragic effects in this case, and it is a phenomenon that has been virtually unreported in the literature. Her fiancé was charged with corroborating Lorraine's false reports of receiving death threats over the telephone. Her fiancé's son readily admitted to lighting both fires. Most curiously, Abby never denied 
the crimes of which Lorraine accused her and corroborated the abduction deception, at Lorraine's request, throughout the duration of two psychiatric hospitalizations (one prior to the kidnapping and one at a forensic hospital after being apprehended at gunpoint) and 16 months of incarceration.

Though we have incomplete information about these individuals, we feel it important to examine, at least in a tentative fashion, the nature of their participation in the prevaricating, as their behaviour may also be psychopathologically significant. First, it is necessary to distinguish their behaviour from naïveté and folie à deux in which there is a similar acceptance and/or endorsement of falsity but either one or both parties, respectively, lack awareness of the falsity. It is clear that Lorraine's associates or partners were in fact lying in their collaboration, as they were conscious of the falsity. Both Abby and Lorraine's fiancé admitted they lied at Lorraine's request, and the three-year-old was probably aware of the fact he did not set the fires.

In order to rate and characterize the pathological significance of this collaboration in lying it seems useful to examine the motives or reasons for it, and to contrast these with the apparent reasons for naïveté and folie à deux. First, the degree of dysfunction associated with naïveté, folie à deux, and collaborative lying seems estimable as a function of the persuasiveness of the liar (or originator of the untruth) and/or the plausibility of the lies or delusions. In other words, complicity with falsity in all of these cases seems somewhat understandable, from the standpoint of normal psychological motivation, if the individual who first espouses the untruth is highly persuasive, has a dominant personality, and/or if the untruth is plausible.

With respect to naïveté specifically, it does not seem that this common tendency to be duped by another should be considered abnormal if the liar is persuasive and/or the lies are plausible. Individuals with PF, like Lorraine, are particularly talented at convincing others (e.g., mental health and legal professionals) to believe in the truthfulness of their lies, and hence acceptance of these lies is not pathological. Akimoto (1997) reported on how one man with PF incited 20,000 followers to religious fanaticism and mass hysteria through his powers of persuasion. Naïveté may involve a pathological process to the extent that there is abandonment of good reason in believing the lies of another (e.g., unquestioning belief in the liar's credibility and/or the lies are highly improbable).

Similarly, with folie à deux the acceptor's belief in the delusions of another seems at least understandable if the principal (originator of the delusion) is persuasive and the delusions are plausible. By definition, however, a delusion may be somewhat implausible as there is often clear contradictory evidence regarding its veracity (cf. APA, 2000). Therefore, the acceptor's complicity with falsity in folie à deux may be pathological to the extent that there is contradictory evidence for delusions or delusions are bizarre.

In contrast to naïveté and folie à deux, the pathological significance of collaboration in lying can only be partly (and not completely) estimated as a 
function of the persuasiveness of the original liar and the plausibility of the lies. Participation in prevarication, for example, is somewhat understandable if the principal is persuasive in convincing others to collaborate, and if the lies they solicit collaboration in propagating are not blatantly transparent (to those who are not privy to their falsity from the outset). There is little doubt that Lorraine was highly persuasive in soliciting collaboration, as she convinced two adults, who otherwise appeared well adjusted, to engage in criminal behaviours to propagate her rather fantastic (though not completely improbable) lies. It seems, however, that such a conscious collaboration in lying should not be considered normal or nonpathological just because the principal was persuasive and the lies had, at least, some plausibility. As with the assessment of original lies as pathological (and consistent with PF), it is important to evaluate the qualitative nature of collaborative lying, and, specifically, whether internal or external motives prompt participation in prevaricating. It is immediately recognizable as non-pathological, for example, if there is clear external gain to be achieved by colluding with the deception. Common examples of this are when an accessory or a witness to a crime colludes in covering up that crime in order to avoid punishment or retaliation, to protect a loved one from punishment, or to obtain monetary or other compensation for their cooperation.

Based on the information available to us, it seems clear that at least some of the collaboration with Lorraine's lying was significantly pathological, as it was not prompted by any obvious or reasonable external goals. It is possible that external goals at least partially prompted the collaborative lying of Lorraine's fiancé and his three-year-old. The three-year-old could have feared Lorraine's disapproval or punishment if he denied her allegations. Her fiancé's participation, though less understandable, may reflect his attempt to ward off a real threat he sensed of losing the relationship if he did not placate Lorraine in prevaricating. It is most puzzling, however, why Abby, a third-year university student with no evident prior or presenting psychiatric problem, maintained her collaboration with Lorraine's lies at such a high cost, and with no apparent gain for herself. If Abby had initially believed Lorraine's story that her participation in the abduction would somehow ensure Lorraine's safety (as an acquaintance of a witness to a local murder), it does not seem reasonable that she never once tried to exonerate herself, even after Lorraine was well and safe enough to testify against her in court (months after the alleged kidnapping). The striking purposelessness of Abby's sustained cooperative lying suggests that internal (vs. external) motives probably prompted and maintained her lying.

This type of purposeless collaboration in lying has rarely been reported in the literature. Weston (1996) reviews the report of a case in which a husband accepted the pathological lies of his wife. Similarly, Enoch and Ball (2001) note that a spouse may passively collude in their partner's 
Munchausen's syndrome by proxy. Healy and Healy (1915) report on a case where there seemed to be no external incentive to account for why a teenage girl and her younger brother colluded in falsely accusing their parents of murdering their younger sister. The only author who seems to have named this phenomenon of purposeless collaborative lying is Deutsch (1922/1982, p. 383), and she calls it 'pseudologie à deux' or 'shared daydreams.' Deutsch reports on a case where a pathological lie originally told by a young boy also met psychological needs for his mother and sister and so all three maintained the lie. As there can be considerable negative consequences associated with this shared pseudology, or collaboration in purposeless deception, this phenomenon is deserving of further empirical and clinical scrutiny.

\section{Conclusions and recommendations}

It is essential that our diagnostic system articulate a more complete definition of all types of pathological lying. For as Healy and Healy (1915, p. 1) point out, 'better definition goes hand in hand with better understanding.' In 1915, Healy and Healy expressed concern that lawyers, and other professional specialists most likely to encounter the phenomenon, had limited knowledge of the disorder. In part due to the lack of diagnostic clarity about PF, it is unfortunate that this may still largely be true. Many authors reporting on $\mathrm{PF}$, for example, have lamented the poor awareness of forensic consequences associated with $\mathrm{PF}$, and they have noted that fantastic criminal liars are still notoriously able to dupe police and disturb the delivery of justice in court proceedings (cf. Akimoto, 1997; Snyder, 1986). If there is better understanding, and more widespread awareness, of characteristics of cases showing this type of behaviour some of the exceedingly costly medical, legal, and social consequences often associated with it can be avoided. In our case report above, improved awareness of PF may have hastened the administration of justice and helped to avert some of the attendant social tragedy.

As noted, there needs to be increased publication of relevant case reports and literature reviews, and further epidemiological research conducted in order to begin unraveling the complexity of PF, and better to characterize its subtypes. Further information on typical age of onset, gender differences, prevalence by socio-economic status, course of illness, and co-morbidity will be valuable to develop a place for this disorder within the current nosological framework. Existing personality disorder diagnoses may not be able to account for the prominence or purposelessness of deception as it is often displayed in PF, and the only other relevant diagnosis currently available can only account for pathological, stereotyped deception about illness (i.e., factitious disorder). Thus, further investigation is needed to determine whether PF would be best conceptualized on Axis I 
of our diagnostic system (e.g., as a primary manifestation of deception about various themes, including illness, identity, and false accusation), or would be better understood as a long-standing personality disorder (i.e., Axis II).

With more epidemiological information and improved diagnostic classification a measured second response can be calculated. A first major step needs to be education of those most likely to encounter this phenomenon: mental health and medical system workers, as well as police and legal professions. One goal of such education would be to develop effective referral mechanisms and interventions for individuals with PF. Interventions might be particularly effective if they are tailored to the specific subtype of $\mathrm{PF}$, and include both individual psychotherapy and family systems work. To date, gentle confrontation about the deception has been suggested (Healy \& Healy, 1915; Weston \& Dalby, 1991), as has the development of more emotionally supportive environments that offer prosocial opportunities for imaginative self-expression, training in impulse control, and education about the adaptive advantages of truthfulness (cf. Davidoff, 1942; Ford et al., 1988; Healy \& Healy, 1915). Anecdotally, Lorraine has reported significant progress through an ongoing program of intensive short-term dynamic psychotherapy.

\section{Acknowledgments}

Cheryl D. Birch gratefully acknowledges her support from a Social Sciences and Humanities Research Council Doctoral Fellowship. The authors express their sincere appreciation to Dr. Stephen Porter for his helpful comments on an early draft of this manuscript.

\section{Note}

1 Names and other identifying information have been changed.

\section{References}

Akimoto, H. (1997). Two cases of pseudologia phantastica: Consideration from the viewpoint of forensic psychiatry. Psychiatry and Clinical Neurociences, 51, 185-195.

American Psychiatric Association. (2000). Diagnostic and statistical manual of mental disorders (4th ed., text revision). Washington, DC: Author.

Davidoff, E. (1942). The treatment of pathological liars. Nervous Child, 1, 358-388.

Deutsch, H. (1982). On the pathological lie (pseudologia phantastica). Fournal of the American Academy of Psychoanalysis, 10, 369-386. (Original work published in German in 1922).

Enoch, M. D., \& Ball, H. N. (2001). Uncommon psychiatric syndromes. New York: Arnold.

Ford, C. V. (1982). Munchausen syndrome. In C. T. H. Friedmann \& R. H. Faguet (Eds.), Extraordinary disorders of human behavior (pp. 15-27). New York: Plenum Press.

Ford, C. V., King, B. H., \& Hollender, M. H. (1988). Lies and liars: Psychiatric aspects of prevarication. American fournal of Psychiatry, 145, 554-562. 
Hardie, T. J., \& Reed, A. (1998). Pseudologia fantastica, factitious disorder and impostership: A deception syndrome. Medicine, Science, and the Law, 38, 198-201.

Healy, W., \& Healy, M. T. (1915). Pathological lying, accusation, and swindling: $A$ study in forensic psychology (Criminal Science Monograph No. 1). Oxford, UK: Little Brown.

King, B. H., \& Ford, C. V. (1987). Pseudologica fantastica. American fournal of Psychiatry, 144, 970.

King, B. H., \& Ford, C. V. (1988). Pseudologia fantastica. Acta Psychiatrica Scandinavica, 77, $1-6$.

Modell, J. G., Mountz, J. M., \& Ford, C. V. (1992). Pathological lying associated with thalamic dysfunction demonstrated by [99mTc] HMPAO SPECT. The fournal of Neuropsychiatry and Clinical Neurosciences, 4, 442-446.

Newmark, N., Adityanjee, \& Kay, J. (1999). Pseudologia fantastica and factitious disorder: Review of the literature and a case report. Comprehensive Psychiatry, 40, 89-95.

Powell, G. E., Gudjonsson, G. H., \& Mullen, P. (1983). Application of the guilty-knowledge technique in a case of pseudologia fantastica. Personality and Individual Differences, 4, 141-146.

Selling, L. (1942). The psychiatric aspects of the pathological liar. Nervous Child, 1, 335-350.

Sharrock, R., \& Cresswell, M. (1989). Pseudologia fantastica: A case study of a man charged with murder. Medicine, Science, and the Law, 29, 323-328.

Snyder, S. (1986). Pseudologia fantastica in the borderline patient. American fournal of Psychiatry, 143, 1287-1289.

Weston, W. A. (1996). Pseudologia fantastica and pathological lying: A forensic issue. In L. B. Schlesinger (Ed.), Explorations in criminal psychopathology: Clinical syndromes with forensic implications (pp. 98-115). Springfield, IL: Charles C. Thomas Publisher Ltd.

Weston, W. A., \& Dalby, J. T. (1991). A case of pseudologia fantastica with antisocial personality disorder. Canadian fournal of Psychiatry, 36, 612-614.

Wiersma, D. (1933). On pathological lying. Character and Personality, 2, 48-61. 
Copyright of Journal of Forensic Psychiatry \& Psychology is the property of Routledge and its content may not be copied or emailed to multiple sites or posted to a listserv without the copyright holder's express written permission. However, users may print, download, or email articles for individual use. 